\title{
ИНСТИТУЦИОНАЛЬНАЯ И СОЦИАЛЬНО-ЭКОНОМИЧЕСКАЯ СРЕДА РЕАЛИЗАЦИИ РЕГИОНАЛЬНОГО ИНВЕСТИЦИОННОГО ПРОЦЕССА
}

\begin{abstract}
АНнотАЦИЯ. Сокращение темпов экономического роста российских регионов актуализирует проблему активизации регионального инвестиционного процесса. В статье приводятся подходы к определению инвестиционного процесса, согласно которым регион выступает в качестве среды его реализации. Подчеркивается, что анализ институциональных и социально-экономических условий региона лежит в основе многих методик по оценке его инвестиционного климата. Выделяются особенности методики, в соответствии с которой обобщающая характеристика инвестиционного климата региона представляет собой среднее значение временного ряда показателей инвестиционной привлекательности. Проведенные расчеты значений инвестиционной привлекательности Забайкальского края, Иркутской области и Республики Бурятия за 2005-2014 гг. показали, что наиболее благоприятным инвестиционным климатом характеризуется Иркутская область. Вследствие более высоких финансово-экономических показателей деятельности предприятий, в Иркутской области наблюдается наибольший удельный вес собственных средств среди всех источников финансирования инвестиций и наибольшие значения доли банковских кредитов в общем объеме привлеченных средств. Сформулирован вывод о том, что высокая стоимость заемного капитала в сочетании с низкими показателями рентабельности служит основным сдерживающим фактором активизации инвестиционного процесса.
\end{abstract}

кЛЮчЕВЫЕ СЛОВА. Региональный инвестиционный процесс; инвестиционная привлекательность; инвестиционный климат; финансовый потенциал; источники финансирования инвестиций.

ИНФОРМАЦИЯ О СТАТЬЕ. Дата поступления 3 октября 2016 г.; дата принятия к печати 20 ноября 2016 г.; дата онлайн-размещения 30 ноября 2016 г.

E. M. Popova

Chita Institute, Baikal State University, Chita, Russian Federation

\section{INSTITUTIONAL AND SOCIO-ECONOMIC ENVIRONMENT OF IMPLEMENTING REGIONAL INVESTMENT PROCESS}

\begin{abstract}
A slowdown in economic growth rate in Russia's regions makes the problem of activating regional investment process topical. The article brings forth the approaches to definition of investment process according to which the region serves as its implementation environment. It lays emphasis that analysis of the region's socio-economic conditions is the basis of many methodologies in assessing its investment climate. It specifies the features of the methodology according to which the generalized characteristic of the region's investment climate presents an average value of tome series of investment attractiveness indicators. Calculations of the values made for investment attractiveness of Zabaikalye Territory, Irkutsk Oblast and Republic of Buryatia over the period of 2005-2014 shows that the most favorable investment climate is characteristic for Irkutsk Oblast. Due to higher financial and economic indicators of business activities, Irkutsk Oblast sees the biggest specific weight of its own funds among all sources of investment financing and biggest values of banking credits in the total volume of the attracted funds. The article formulates a conclusion that the high cost of the borrowed funds in combination with low profitability indicators serves as the main limiting factor of activating the investment process.
\end{abstract}

\section{Baikal Research Journal}


KEYWORDS. Regional investment process; investment attractiveness; investment climate; financial potential; sources of funding investments.

ARTICLE INFO. Received October 3, 2016; accepted October 20, 2016; available online November 30, 2016.

Инвестиционный процесс можно определить как последовательность действий субъекта инвестирования по извлечению дохода в результате адаптации ресурсов к условиям функционирования в конкретной сфере деятельности [1, с. 98]. В данном определении содержится два ключевых положения, касающихся сущности инвестиционного процесса. Во-первых, основной целью инвестиционного процесса, инициируемого экономическими агентами, выступает получение дохода. В свою очередь, величина потенциального дополнительного дохода зависит от величины предельной эффективности капитала (в теории Дж. Кейнса), или более известной в современной экономической теории как внутренней нормы доходности проекта. Если же планируется осуществлять финансирование инвестиций за счет заемных средств, то принципиальное значение приобретает ставка ссудного процента. Во-вторых, инвестиционный процесс, ориентированный, прежде всего, на извлечение дохода, реализуется в конкретной институциональной среде и при определенных социально-экономических условиях, и чем выше качественные характеристики институциональной среды, чем более благоприятными являются социально-экономические условия, тем по определению активнее протекают инвестиционные процессы. $\mathcal{K}$ основным характеристикам институциональной среды следует отнести стабильность и надежность политического режима, нормативно-правовой базы, в первую очередь, инвестиционного законодательства. К социально-экономическим условиям, влияющим на принятие инвестиционных решений, можно отнести состояние инфраструктуры, наличие квалифицированных трудовых ресурсов, доступность кредитных ресурсов, темпы инфляции, уровень жизни населения, а именно величина денежных доходов населения и т. д. Регион с его территориальной и бюджетной обособленностью, наличием собственных органов исполнительной и законодательной власти, а также совокупностью более или менее общих природных, исторических, демографических, экономических условий часто рассматривается в качестве непосредственной среды реализации инвестиционных процессов [2, с. 130]. Таким образом, в каждом отдельном регионе формируется своя институциональная среда и совокупность социально-экономических условий, которые задают рамки для протекающих инвестиционных процессов.

C точки зрения системного подхода, применяемого при анализе инвестиционного процесса в монографии В. Г. Кобылинской, инвестиционный процесс рассматривается как процесс, обеспечивающий взаимодействие основных элементов инвестиционной подсистемы региональной системы, а именно, инвесторов, органов власти региона, предприятий и организаций инвестиционной инфраструктуры (коммерческие банки, страховые организации, негосударственные пенсионные фонды) [3, с. 44]. В свою очередь, исследование инвестиционной подсистемы требует выявления ее взаимосвязи с другими подсистемами региональной системы, такими как эколого-географической, производственной, социальной, финансовой, информационной и управляющей. При этом каждая из подсистем представляет собой потенциалы и риски, или условия, реализации инвестиционного процесса. Так, эколого-географическая подсистема характеризуется как обеспеченность региона природными ресурсами, производственная подсистема есть совокупность предприятий и реализуемых ими инвестиционных проектов, социальная подсистема определяется через количество и качество трудовых ресурсов, а финансовая через оценку имеющихся финансовых ресурсов, в том числе, предоставляемых организациями инвестиционной инфраструктуры. Наконец, управляющая подсистема есть инсти-

\section{Baikal Research Journal}

электронный научный журнал Байкальского государственного университета 
туты исполнительной и законодательной власти региона, определяющие правовые рамки, и задающие «правила игры» региональной системы в целом.

Состояние управляющей подсистемы играет далеко не последнюю роль в принятии инвестиционных решений. В монографии С. Н. Гусева была предложена достаточно интересная иерархия потребностей инвестора, построенная по принципу известной пирамиды А. Маслоу [4, с. 151]. В основании данной пирамиды лежит потребность в инвестиционной деятельности, которая появляется, если участники инвестиционного процесса уверены в соблюдении и защите своих прав и выполнении предоставленных им гарантий. То есть, чем более прозрачным и стабильным является региональное законодательство, чем большей предсказуемостью и ответственностью характеризуются действия региональных властей в сфере инвестиционного сотрудничества, построенного на взаимовыгодной основе, тем, в конечном счете, благоприятнее институциональная среда реализации инвестиционного процесса.

Таким образом, с позиции системного подхода, динамика инвестиционного процесса, связывающего элементы инвестиционной подсистемы, во многом зависит от состояния других подсистем, которые, в сущности, и формируют институциональную среду и социально-экономические условия протекающих инвестиционных процессов.

Именно ключевые аспекты институциональной среды и социально-экономические условия лежат в основе оценки инвестиционной привлекательности (инвестиционного климата) региона. В настоящее время существует множество методик по оценке инвестиционной привлекательности и инвестиционного климата. Актуальность разработки и усовершенствования данных методик сопряжена с тем, что инвестиции выступают необходимым условием как расширенного воспроизводства, так и изменения хозяйственной структуры региона. В свою очередь, инвестиционная активность подвержена воздействию многочисленных факторов, которые необходимо учитывать, а также подвергать оценки. Исходя из этого, с целью управления инвестиционным процессом на региональном уровне, посредством создания благоприятных условий и устранения слабых мест, целесообразно представление региона как системы, состоящей из инвестиционной подсистемы, которая выступает объектом управления, и ряда других подсистем, которые определяют среду реализации инвестиционного процесса (совокупность потенциалов и рисков).

Одной из наиболее приемлемых методик по оценке состояния среды реализации инвестиционного процесса на региональном уровне является методика, основанная на временном подходе (расширенном рисковом), согласно которому инвестиционный климат представляет собой инвестиционную привлекательность в динамическом аспекте [5, с. 41]. То есть, для определения состояния инвестиционного климата необходимы данные о состоянии инвестиционной привлекательности региона за период не менее пяти лет. В основе предложенной методики лежат элементы индикативного анализа и подход, используемый рейтинговым агентством «Эксперт PA», в соответствии с которым инвестиционная привлекательность региона складывается из инвестиционного потенциала, включающего девять частных потенциалов, и инвестиционного риска, состоящего из семи видов частных рисков [6, с. 16]. В свою очередь, каждый частный потенциал и каждый частный риск характеризуется совокупностью статистических показателей, преимущественно относительными, а именно, в расчете на душу населения, на одну организацию, по отношению к ВРП, к собственным доходам регионального бюджета и т. д., поскольку являются наиболее приемлемыми для проведения сравнительного анализа. В приведенной ниже табл. 1 представлены частные индикаторы инвестиционного потенциала и формирующие их показатели, которые, на наш взгляд, наилучшим образом раскрывают сущность отдельных составляющих инвестиционного потенциала.

\section{Baikal Research Journal}

электронный научный журнал Байкальского государственного университета 
Набор показателей, характеризующих частные индикаторы инвестиционного потенциала

\begin{tabular}{|c|c|c|}
\hline $\begin{array}{l}\text { Индика- } \\
\text { тор }\end{array}$ & $\begin{array}{c}\text { Весовой } \\
\text { коэффи- } \\
\text { циент }\end{array}$ & Показатель \\
\hline \begin{tabular}{l|} 
Производ- \\
ственный \\
потенциал
\end{tabular} & 0,7 & ВРП на душу населения, p. \\
\hline \multirow[t]{5}{*}{$\begin{array}{l}\text { Трудовой } \\
\text { потенциал }\end{array}$} & \multirow[t]{5}{*}{0,7} & $\begin{array}{l}\text { Население в трудоспособном возрасте по отношению ко всему населе- } \\
\text { нию региона, \% }\end{array}$ \\
\hline & & Ожидаемая продолжительность жизни при рождении, лет \\
\hline & & $\begin{array}{l}\text { Естественный прирост населения на } 1 \text { тыс. чел., чел. (если наблюдается } \\
\text { естественная убыль, то показатель принимает нулевое значение) }\end{array}$ \\
\hline & & $\begin{array}{l}\text { Численность студентов государственных и муниципальных профессио- } \\
\text { нальных образовательных организаций, обучающихся по программам } \\
\text { подготовки специалистов среднего звена на } 10 \text { тыс. чел. населения, чел. }\end{array}$ \\
\hline & & $\begin{array}{l}\text { Численность студентов, обучающихся по программам бакалавриата, } \\
\text { специалитета, магистратуры на } 10 \text { тыс. чел. населения, чел. }\end{array}$ \\
\hline \multirow{4}{*}{\begin{tabular}{l|} 
Потреби- \\
тельский \\
потенциал
\end{tabular}} & \multirow[t]{4}{*}{0,65} & Среднедушевые денежные доходы, р. \\
\hline & & Потребительские расходы в среднем на душу населения, p. \\
\hline & & Число собственных легковых автомобилей на 1 тыс. чел. населения, шт. \\
\hline & & $\begin{array}{l}\text { Общая площадь жилых помещений, приходящаяся в среднем на } \\
\text { одного жителя, } \text { м }^{2}\end{array}$ \\
\hline \multirow{2}{*}{\begin{tabular}{l|} 
Инфра- \\
струк- \\
турный \\
потенциал
\end{tabular}} & \multirow[t]{2}{*}{0,6} & $\begin{array}{l}\text { Плотность автомобильных дорог общего пользования с твердым } \\
\text { покрытием, км путей на } 1 \text { тыс. км² территории }\end{array}$ \\
\hline & & $\begin{array}{l}\text { Наличие квартирных телефонных аппаратов сети общего пользования } \\
\text { на } 1 \text { тыс. чел. городского населения, шт. }\end{array}$ \\
\hline \multirow[t]{4}{*}{$\begin{array}{l}\text { Финан- } \\
\text { совый } \\
\text { потенциал }\end{array}$} & \multirow[t]{4}{*}{0,6} & $\begin{array}{l}\text { Сальдированный финансовый результат деятельности организаций в } \\
\text { расчете на одну организацию, тыс. р. (если отрицательное значение, то } \\
\text { показатель принимает нулевое значение) }\end{array}$ \\
\hline & & $\begin{array}{l}\text { Вклады (депозиты) юридических и физических лиц в рублях, привлечен- } \\
\text { ные кредитными организациями в расчете на душу населения, млн р. }\end{array}$ \\
\hline & & $\begin{array}{l}\text { Профицит консолидированного бюджета по отношению к ВРП, \% (если } \\
\text { дефицит, то показатель принимает нулевое значение) }\end{array}$ \\
\hline & & Доля собственных доходов в доходной части регионального бюджета, \% \\
\hline \multirow{2}{*}{$\begin{array}{l}\text { Инсти- } \\
\text { туцио- } \\
\text { нальный } \\
\text { потенциал }\end{array}$} & \multirow[t]{2}{*}{0,4} & $\begin{array}{l}\text { Число малых предприятий по отношению к общему числу предприя- } \\
\text { тий, \% }\end{array}$ \\
\hline & & $\begin{array}{l}\text { Число индивидуальных предпринимателей по отношению к численно- } \\
\text { сти населения, \% }\end{array}$ \\
\hline \multirow{2}{*}{$\begin{array}{l}\text { Иннова- } \\
\text { ционный } \\
\text { потенциал }\end{array}$} & \multirow[t]{2}{*}{0,4} & $\begin{array}{l}\text { Количество организаций, осуществляющих технологические, организа- } \\
\text { ционные, маркетинговые инновации в общем числе организаций, \% }\end{array}$ \\
\hline & & $\begin{array}{l}\text { Объем инновационных товаров, работ, услуг в общем объеме товаров, } \\
\text { работ, услуг, \% }\end{array}$ \\
\hline \multirow{4}{*}{$\begin{array}{l}\text { Природ- } \\
\text { но-ре- } \\
\text { сурсный } \\
\text { потенциал }\end{array}$} & \multirow[t]{4}{*}{0,35} & $\begin{array}{l}\text { Объем добычи топливно-энергетических полезных ископаемых в рас- } \\
\text { чете на одного жителя, тонн условного топлива }\end{array}$ \\
\hline & & $\begin{array}{l}\text { Объем добычи минеральных полезных ископаемых в расчете на одно- } \\
\text { го жителя, тыс. р. (в сопоставимых ценах) }\end{array}$ \\
\hline & & Площадь сельскохозяйственных угодий в расчете на одного жителя, га \\
\hline & & Общий запас древесины в расчете на одного жителя, тыс. м $^{3}$ \\
\hline \multirow{3}{*}{$\begin{array}{l}\text { Туристи- } \\
\text { ческий } \\
\text { потенциал }\end{array}$} & \multirow[t]{3}{*}{0,05} & Объем оказанных туристских услуг в расчете на одного жителя, p. \\
\hline & & $\begin{array}{l}\text { Объем оказанных услуг гостиниц и аналогичных средств размещения } \\
\text { на одного жителя, р. }\end{array}$ \\
\hline & & $\begin{array}{l}\text { Общий объем туристского потока в регионе (количество российских и } \\
\text { иностранных туристов), тыс. чел. }\end{array}$ \\
\hline
\end{tabular}

\section{Baikal Research Journal}


В силу многогранности самих понятий «инвестиционная привлекательность» и «инвестиционный климат», в ходе их оценки задействуются разнородные статистические показатели с различными единицами измерения. Для того, чтобы представить данные показатели в сопоставимом виде, а впоследствии произвести расчеты частных и интегральных индикаторов, необходимо вычислить их нормализованные значения, выраженные в относительных единицах измерения (долях единицы или процентах) [5, с. 82]. Для исчисления нормализованных значений отдельных показателей в качестве базы нами использовались максимальные значения конкретных показателей, зафиксированные среди всех регионов за каждый год исследования, а не в первый год исследования, как было предложено в авторской методике, поскольку, на наш взгляд, это позволяет получить наиболее реалистичные оценки и отследить изменение состояния инвестиционной привлекательности регионов в динамике.

Стоит отметить, что при вычислении отдельного частного индикатора будем исходить из того, что показатели, его характеризующие, имеют равные веса, то есть, признается их равнозначный вклад в формирование частного индикатора. Соответственно, будем использовать формулу средней арифметической простой. При определении интегральных индикаторов воспользуемся значениями весов вклада соответствующих частных потенциалов и частных рисков в совокупный инвестиционный потенциал и инвестиционный риск, полученными экспертным путем рейтинговым агентством «Эксперт РА». В целом логику исчисления интегральных показателей можно изложить следующим образом: после определения частных потенциалов (рисков) по каждому региону строится лепестковая диаграмма, по осям которой откладываются значениями потенциалов (рисков). В результате получаем фигуру, представляющую собой совокупность треугольников, сторонами которых будут отрезки осей диаграммы и соединительные линии. Интегральный показатель инвестиционного потенциала (инвестиционного риска) есть результат отношения площади фигуры, соответствующей конкретному региону, к площади фигуры, соответствующей некому эталонному региону, которому присваиваются максимальные значения показателей, зафиксированные среди всех регионов в каждый год исследования.

Таким образом, суть данной методики можно изложить так: как известно, в силу ограниченности ресурсов всегда приходится делать экономический выбор, который сводится к выбору наиболее эффективного варианта среди имеющихся альтернатив. Потенциальный инвестор также сталкивается с проблемой выбора не только непосредственного объекта инвестирования, но и территории (региона), где будет осуществляться вложение инвестиционных ресурсов. Например, инвестору необходимо выбрать регион из трех на настоящий момент возможных (приемлемых) для него субъектов РФ, расположенных по соседству: Забайкальский край, Иркутская область и Республика Бурятия. Для решения этой задачи можно оценить инвестиционный потенциал и инвестиционный риск каждого региона, сформировать картину о состоянии инвестиционного климата, а затем сделать выбор в пользу того или иного региона. Как уже было упомянуто выше, сравнивается конкретный регион с фактическими статистическими показателями с неким эталонным регионом, который характеризуется максимально возможным инвестиционным потенциалом или инвестиционным риском. Математически значения инвестиционного потенциала и инвестиционного риска определяются через отношение площадей двух фигур, при этом знаменатель всегда больше, поэтому они все меньше единицы. Экономическая интерпретация полученных значений сводится к следующему: чем ближе значение потенциала или риска к единице, тем выше инвестиционный потенциал или инвестиционный риск региона. Однако,

\section{Baikal Research Journal}

электронный научный журнал Байкальского государственного университета 
стоит подчеркнуть, что подобные оценки имеют смысл только для ограниченного числа регионов, а именно, для тех, данные по которым используются в расчетах. То есть, если мы расширим круг предполагаемых регионов для инвестирования, то и значения инвестиционного потенциала и инвестиционного риска, первоначально полученные при проведении расчетов по трем регионам, изменятся.

В завершении изложения ключевых аспектов применяемой методики, остановимся на обосновании состава показателей таких частных потенциалов, как финансовый и природно-ресурсный потенциал. Что касается финансового потенциала, то включение таких показателей как сальдированный финансовый результат деятельности организаций в расчете на одну организацию, размер вкладов (депозитов) юридических и физических лиц в рублях, привлеченные кредитными организациями в расчете на душу населения, и доля собственных доходов в доходной части регионального бюджета обусловлено тем, что состояние потенциальных источников финансирования инвестиционных расходов выступает неотъемлемой характеристикой существующих в регионе финансовых условий реализации инвестиционных процессов. Так основными источниками финансирования инвестиций выступают прибыль организаций (информация о возможности предприятий инвестировать за счет собственных средств в масштабах региона может быть получена исходя из данных по сальдированному финансовому результату деятельности организаций), заемные средства, например, банковские кредиты (именно организованные сбережения населения в виде банковских вкладов выступают одной из основных составляющих ресурсной базы банковского кредитования, то есть, чем больше сумма банковских вкладов, тем выше кредитные возможности банков и доступнее заемный капитал), а также субсидии правительства (чем больше доля собственных доходов в доходной части регионального бюджета, тем более устойчивыми оказываются источники формирования средств для предоставления субсидий).

Что касается природно-ресурсного потенциала, то мы придерживаемся той точки зрения, что природно-ресурсный потенциал субъектов РФ как компонент инвестиционного потенциала целесообразно оценивать через степень обеспеченности природным капиталом. Под природно-ресурсным потенциалом понимается совокупность природных ресурсов, которые в будущем могут быть вовлечены в хозяйственный оборот, и те природные ресурсы, которые фактически задействованы в производстве [7, с. 56]. Таким образом, при его оценке рассчитываются следующие показатели: объем добычи топливно-энергетических полезных ископаемых в расчете на одного жителя в тоннах условного топлива (при расчетах использовались коэффициента пересчета, утвержденные Росстатом), объем добычи минеральных полезных ископаемых в расчете на одного жителя (в сопоставимых ценах, а именно, ценах 2005 г., здесь номинальные показатели каждого года корректировались на базисные индексы цен), площадь сельскохозяйственных угодий в расчете на одного жителя и общий запас древесины в расчете на одного жителя [8, с. 59]. Тот факт, что учитываются объемы добычи полезных ископаемых в каждом регионе, соответствует общим принципам оценки инвестиционного потенциала, который, как уже неоднократно отмечалось, отражает институциональные и социально-экономические условия реализации инвестиционных процессов. В свою очередь, степень обеспеченности региона реально функционирующей ресурсно-сырьевой базой также выступает фактором, прямо или косвенно влияющим на инвестиционную активность.

Как уже отмечалось выше, для определения состояния инвестиционного климата регионов необходимо рассчитать значения инвестиционной привлекательности за некоторый период времени, мы взяли период 2005-2014 гг. Объектами анализа выступили три соседних субъекта Сибирского федерального округа: За-

\section{Baikal Research Journal}

электронный научный журнал Байкальского государственного университета 
байкальский край, Иркутская область и Республика Бурятия. Полученные значения интегральных показателей свидетельствуют о том, что, несмотря на снижение в отдельные годы, наибольшим инвестиционным потенциалом обладает Иркутская область, а наименьшим - Забайкальский край (табл. 2-4).

Таблица 2

Оиенка инвестищионной привлекательности Забайкальского края в 2005-2014 22.

\begin{tabular}{|l|c|c|c|c|c|c|c|c|c|c|}
\hline \multicolumn{1}{|c|}{ Показатель } & \multicolumn{1}{|c|}{2005} & 2006 & 2007 & 2008 & 2009 & 2010 & 2011 & 2012 & 2013 & \multicolumn{2}{c|}{2014} \\
\hline $\begin{array}{l}\text { Инвестиционный } \\
\text { потенциал }\end{array}$ & 0,464 & 0,529 & 0,499 & 0,531 & 0,545 & 0,552 & 0,597 & 0,557 & 0,554 & 0,551 \\
\hline $\begin{array}{l}\text { Инвестиционный } \\
\text { риск }\end{array}$ & 0,58 & 0,57 & 0,57 & 0,62 & 0,60 & 0,60 & 0,74 & 0,62 & 0,60 & 0,60 \\
\hline
\end{tabular}

Таблица 3

Оценка инвестиционной привлекательности Иркутской области в 2005-2014 22.

\begin{tabular}{|l|r|r|r|r|r|r|r|r|r|r|}
\hline \multicolumn{1}{|c|}{ Показатель } & \multicolumn{1}{|c|}{2005} & 2006 & 2007 & 2008 & \multicolumn{1}{c}{2009} & 2010 & 2011 & 2012 & 2013 & \multicolumn{1}{c|}{2014} \\
\hline $\begin{array}{l}\text { Инвестиционный } \\
\text { потенциал }\end{array}$ & 0,662 & 0,608 & 0,452 & 0,663 & 0,714 & 0,689 & 0,72 & 0,757 & 0,746 & 0,723 \\
\hline $\begin{array}{l}\text { Инвестиционный } \\
\text { риск }\end{array}$ & 0,70 & 0,76 & 0,68 & 0,76 & 0,54 & 0,60 & 0,69 & 0,63 & 0,64 & 0,63 \\
\hline
\end{tabular}

Оценка инвестищионной привлекательности Республики Бурятия

Таблица 4 в 2005-2014 22.

\begin{tabular}{|c|c|c|c|c|c|c|c|c|c|c|}
\hline Показатель & 2005 & 2006 & 2007 & 2008 & 2009 & 2010 & 2011 & 2012 & 2013 & 2014 \\
\hline $\begin{array}{l}\text { Инвестиционный } \\
\text { потенциал }\end{array}$ & 0,516 & 0,591 & 0,659 & 0,704 & 0,618 & 0,602 & 0,618 & 0,608 & 0,599 & 0,60 \\
\hline $\begin{array}{l}\text { Инвестиционный } \\
\text { оиск }\end{array}$ & 0 , & 0 & 0,44 & 0 & 0,43 & 0,45 & 0,43 & 0,49 & 0,36 & 0 , \\
\hline
\end{tabular}

Данный вывод подтверждают и исчисленные средние значения уровней представленных динамических рядов (табл. 5).

Таблица 5

Усредненные оценки инвестиционного потенцила и инвестищионного риска субъектов РФ за 2005-2014 г2.

\begin{tabular}{|l|r|r|r|r|}
\hline \multirow{2}{*}{ Регион } & \multicolumn{2}{|c|}{ Среднее значение уровня } & \multicolumn{2}{|c|}{ Средний абсолютный прирост } \\
\cline { 2 - 5 } & $\begin{array}{c}\text { Инвестиционный } \\
\text { потенциал }\end{array}$ & $\begin{array}{l}\text { Инвестиционный } \\
\text { риск }\end{array}$ & $\begin{array}{c}\text { Инвестиционный } \\
\text { потенциал }\end{array}$ & $\begin{array}{c}\text { Инестиционный } \\
\text { риск }\end{array}$ \\
\hline Забайкальский край & 0,538 & 0,61 & 0,01 & 0,002 \\
\hline Иркутская область & 0,673 & 0,663 & 0,007 & $-0,008$ \\
\hline Республика Бурятия & 0,612 & 0,456 & 0,01 & $-0,012$ \\
\hline
\end{tabular}

В целом же нельзя сказать, что значения инвестиционных потенциалов трех регионов резко контрастируют, тем не менее, Иркутская область и Республика Бурятия являются ближайшими конкурентами в борьбе за привлечение инвестиционных ресурсов, а Забайкальский край пока остается менее привлекательным на фоне двух соседних регионов.

В то же время Иркутская область имеет и самые высокие значения инвестиционного риска, а наименьшим инвестиционным риском характеризуется Республика Бурятия (см. табл. 2-4). При этом рассчитанные значения среднего абсолютного прироста интегрального индикатора инвестиционного риска показывают, что именно в Республике Бурятия в наибольшей степени в среднем каждый год снижался инвестиционный риск (см. табл. 5). По усредненным оценкам в течение 2005-2014 гг. снижался и инвестиционный риск в Иркутской области, хотя и не-

\section{Baikal Research Journal}

электронный научный журнал Байкальского государственного университета 
значительно. Напротив, в Забайкальском крае, где уровень инвестиционного риска сопоставим с уровнем риска в Иркутской области, отмечается противоположная тенденция, состоящая в ежегодном небольшом росте инвестиционного риска.

Исходя из выше изложенного, прежде всего, оперируя средними значениями инвестиционного потенциала и инвестиционного риска, которыми характеризуется исследуемый период, мы не можем однозначно заключить, какой из регионов имеет наиболее благоприятный инвестиционный климат. Данный вопрос можно разрешить, обратившись к дополнительному анализу инвестиционного потенциала и инвестиционного риска регионов в разрезе частных индикаторов. То есть, чем выше частные потенциалы одного региона, имеющие наибольшие весовые коэффициенты, тем лучше его инвестиционный климат по сравнению с другим. Соответственно, чем ниже частные риски одного региона, имеющие наибольшие весовые коэффициенты, тем лучше его инвестиционный климат по сравнению с другим.

Мы будем сравнивать Иркутскую область и Республику Бурятию. В качестве частных потенциалов, по которым будет проводиться сравнение, выберем первых пять (производственный, трудовой, потребительский, инфраструктурный и финансовый), что касается частных рисков, то возьмем первых три (экономический, финансовый и правовой), так как они имеют наибольшие весовые коэффициенты, a, следовательно, отличаются наибольшей значимостью при определении инвестиционной привлекательности. Если в большинстве своем за весь период исследования (в результате сопоставления значений за каждый год) частный потенциал оказался больше, то присваиваем региону 1 , если меньше - 0 , если соответствующий частный риск оказался больше, то присваиваем региону 0 , если меньше -1 , и находим общую сумму присвоенных значений. Наиболее благоприятным инвестиционным климатом будет обладать тот регион, у которого общая сумма значений окажется больше. Результаты приведены в табл. 6. Таким образом, наиболее благоприятным инвестиционным климатом характеризуется Иркутская область.

Таблица 6

Сравнение инвестищионного климата Иркутской области и Республики Бурятия в разрезе частных потенииалов и рисков

\begin{tabular}{|l|c|c|}
\hline \multicolumn{1}{|c|}{ Индикатор } & Иркутская область & Республика Бурятия \\
\hline Производственный потенциал & 1 & 0 \\
\hline Трудовой потенциал & 0 & 1 \\
\hline Потребительский потенциал & 1 & 0 \\
\hline Инфраструктурный потенциал & 1 & 0 \\
\hline Финансовый потенциал & 1 & 0 \\
\hline Экономический риск & 0 & 1 \\
\hline Финансовый риск & 0 & 1 \\
\hline Правовой риск & 1 & 0 \\
\hline Всего & 5 & 3 \\
\hline
\end{tabular}

Продолжая оценку инвестиционного климата регионов в разрезе отдельных потенциалов и рисков, считаем необходимым более подробно остановиться на финансовом потенциале как одном из ключевых потенциалов, определяющих состояние инвестиционного климата [9, с. 5]. Как уже отмечалось выше, наиболее высокий финансовый потенциал имеет Иркутская область, где сальдированный финансовый результат деятельности предприятий в расчете на одну организацию за 2005-2014 гг. составил в среднем 1447,9 тыс. р., в то время как в Забайкальском крае этот показатель равен 83,1 тыс. р., в Республике Бурятия $-474,5$ тыс. p. ${ }^{1}$

1 Федеральная служба государственной статистики : офиц. сайт / Росстат. URL: http://www. gks.ru/wps/wcm/connect/rosstat_main/rosstat/ru/statistics/publications/catalog/doc_1138623506156.

\section{Baikal Research Journal}


Поэтому, учитывая, что прибыль является одним из основных внутренних источников финансирования инвестиций, вполне закономерным можно считать тот факт, что среди всех источников финансирования инвестиций в Иркутской области наибольший удельный вес занимают собственные средства $(56,18 \%)$, что больше среднероссийского показателя за исследуемый период $(43,68$ \%), в Забайкальском крае это показатель почти в два раза меньше $(29,1 \%)$, в Республике Бурятия - 33,51 \% (табл. 7).

Таблица 7

Средние значения удельного веса источников финансирования инвестищий в 2005-2014 22.

\begin{tabular}{|l|r|r|r|r|}
\hline \multicolumn{1}{|c|}{ Регион } & Собственные & Привлеченные & \multicolumn{2}{|c|}{ Из них: } \\
\cline { 4 - 5 } & средства & средства & Кредиты банков & Бюджетные средства \\
\hline Забайкальский край & 29,10 & 70,90 & 2,57 & 28,60 \\
\hline Иркутская область & 56,18 & 43,92 & 7,87 & 10,00 \\
\hline Республика Бурятия & 33,51 & 66,49 & 5,29 & 39,54 \\
\hline
\end{tabular}

Стоит отметить и то, что вследствие высоких финансовых показателей деятельности предприятий, из трех рассматриваемых регионов именно в Иркутской области отмечаются наибольшие значения доли банковских кредитов в общем объеме привлеченных средств, в среднем 7,87 \% , что в целом соответствует среднероссийскому показателю $9,32 \%{ }^{2}$. При этом, если в Иркутской области бюджетные средства занимают около 10 \% в общем объеме привлеченных средств, то в Забайкальском крае и Республике Бурятия почти треть всех привлеченных средств приходится на бюджетные средства (см. табл. 7). Данные цифры достаточно ярко характеризуют проблемы современной российской модели инвестирования, состоящие в невысокой роли банковского сектора в финансировании инвестиционного процесса.

Как уже было замечено, доля банковских кредитов составляет около 10 \% от всего объема привлеченных средств, в то время как в развитых странах этот показатель превышает 50 \% [10, с. 58]. В качестве основной причины сложившейся ситуации можно назвать высокие ставки по кредитам, превосходящие средние показатели рентабельности активов [11, с. 12]. Так по данным Всемирного банка за 2005-2014 гг. среднегодовая ставка по кредитам в России составила 10,75 \%

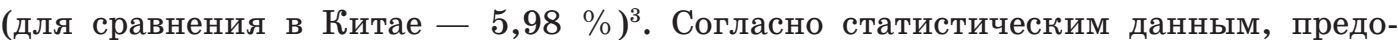
ставленным Банком России, средневзвешенная процентная ставка по кредитам нефинансовым организациям составляет около $14 \%$, а субъектам малого и среднего предпринимательства $-16 \%{ }^{4}$. Подобная ситуация связана, прежде всего, с проведением Банком России достаточно жесткой денежно-кредитной политики, следствием которой является хронический недостаток долгосрочных пассивов у коммерческих банков, которые необходимы для финансирования инвестиционного процесса $[12$, с. 6]. Одним из основных источников пополнения ресурсной базы регионального банковского сектора, от размеров и срочной структуры которой зависят его кредитные возможности, остаются вклады физических и юридических лиц (около 50 \%) . Исходя из этого, еще одним подтверждением более высокого финансового потенциала Иркутской области по сравнению с двумя другими регионами, является то, что за 2005-2014 гг. средний размер вкладов юридических и физических лиц, привлеченных кредитными организациями в расчете на душу

2 URL: http://www.gks.ru/wps/wcm/connect/rosstat_main/rosstat/ru/statistics/publications/ catalog/doc_1138623506156.

${ }^{3}$ Всемирный банк : офиц. сайт. URL: http://data.worldbank.org/indicator/FR.INR.LEND.

${ }^{4}$ Центральный Банк РФ : офиц. сайт. URL: https://www.cbr.ru/statistics/?PrtId=int_rat.

\section{Baikal Research Journal}

электронный научный журнал Байкальского государственного университета 
населения, в Иркутской области составил 34,5 тыс. р., в Забайкальском крае 20,7 тыс. р., в Республике Бурятия - 19,7 тыс. p. ${ }^{5}$ Однако, возвращаясь к проблеме срочной структуры банковских пассивов, стоит привести цифры, которые свидетельствуют о недостатке «длинных денег» для финансирования инвестиций: доля депозитов физических лиц со сроком привлечения от 1 до 3 лет составляет в среднем $23,9 \%$, а свыше 3 лет - 0,54 \% ; доля депозитов нефинансовых организаций со сроком привлечения от 1 до 3 лет составляет в среднем $0,23 \%$, а свыше 3 лет $-0,01 \%{ }^{6}$.

Не единожды сформулированный вывод о более высоком финансовом потенциале Иркутской области можно обосновать и тем фактом, что Иркутская область имеет более развитый рынок ценных бумаг по сравнению с Республикой Бурятия и Забайкальским краем. Традиционно предприятия Иркутской области отличаются большей эмиссионной активностью $[13$, с. 63]. Как известно, эмиссия ценных бумаг является одним из источников финансирования инвестиций, а рынок ценных бумаг в странах с англосаксонской моделью преобразования сбережений в инвестиции, играет роль главного института инвестиционной инфраструктуры. В свою очередь, возвращаясь к особенностям сложившейся в России модели финансирования инвестиций, следует отметить, что значение рынка ценных бумаг как механизма привлечения инвестиций, в большинстве российских регионов (в том числе в Иркутской области, Республике Бурятия и Забайкальском крае) достаточно мало, и несмотря на невысокую роль банковской системы в финансировании регионального инвестиционного процесса, основным финансовым посредником все же остаются банки. Именно банки рассматриваются в качестве ключевого субъекта аккумулирования свободных денежных средств и инвестирования в реальный сектор экономики, и в работах С. А. Бахматова [14, с. 78].

Таким образом, динамика регионального инвестиционного процесса во многом определяется состоянием инвестиционного климата, прежде всего, такой его составляющей как финансовый потенциал. Поэтому во многих современных научных публикациях формулируются предложения о необходимости создания на основе зарубежного опыта системы долгосрочного инвестиционного рефинансирования, центральным звеном которой может стать Банк России или специальные государственные институты. Ведь высокие темпы экономического роста ряда азиатских стран, в первую очередь, Китая в немалой степени обусловлены существованием внутренних механизмов финансирования инвестиций, а именно предоставлением через государственные банки, выполняющие роль институтов развития, долгосрочных кредитных ресурсов под приемлемый процент в целях активизации инвестиционного процесса.

\section{Список использованной литературы}

1. Мессель Е. О. Управление инвестиционным процессом на региональном уровне / Е. О. Мессель // Проблемы современной экономики. - 2015. - № 2. - С. 97-102.

2. Савон И. В. Системный подход к управлению инвестиционными процессами на региональном уровне / И. В. Савон // Финансовые исследования. - 2012. - № 1. - С. 128-132.

3. Кобылинская Г. В. Региональная инвестиционная система: тенденции развития и направления совершенствования / Г. В. Кобылинская, А. Н. Чапаргина. - Апатиты : Издво Кольск. науч. центра РАН, 2013. - 164 с.

4. Гусев С. Н. Инвестиционный процесс в отечественной экономике и пути повышения эффективности государственного регулирования национального накопления / С. Н. Гусев. - Казань : Артифакт, 2014. - 204 с.

${ }^{5}$ URL: http://www.gks.ru/wps/wcm/connect/rosstat_main/rosstat/ru/statistics/publications/ catalog/doc_1138623506156.

${ }^{6}$ URL: https://www.cbr.ru/statistics/?PrtId=int_rat.

\section{Baikal Research Journal}


5. Литвинова В. В. Инвестиционная привлекательность и инвестиционный климат региона : монография / В. В. Литвинова. - М. : Финансов. ун-т, 2013. - 116 с.

6. Александров Г. А. Инвестиционный климат и инвестиционные риски: методология анализа взаимосвязи и оценки / Г. А. Александров, И. В. Вякина, Г. Г. Скворцова // Национальные интересы: приоритеты и безопасность. - 2014. - № 22 (259). - С. 12-22.

7. Пыхов П. А. Диагностика природно-ресурсного капитала территории / П. А. Пыхов // Экономика региона. - 2013. - № 2. - С. 55-63.

8. Мызин А. Л. Моделирование состояния национального богатства регионов России / А. Л. Мызин, А. И. Татаркин // Экономика региона. - 2013. - № 4. - С. 53-65.

9. Игонина Л. Л. Финансовый потенциал инвестиционного процесса в российской экономике / Л. Л. Игонина // Дайджест-Финансы. - 2016. — № 2 (238). — С. 2-14.

10. Кокушкина И. В. Регион в системе современных инвестиционных процессов: монография / И. В. Кокушкина. - СПб. : Спец. лит., 2014. - 256 с.

11. Тютюкина Е. Б. Влияние кредитного и налогового факторов на развитие инвестиционной деятельности омпаний базовых отраслей экономики / Е. Б. Тютюкина, Т. Н. Седаш // Финансы и кредит. - 2014. - № 19 (595). — С. 9-16.

12. Николаев М. А. Анализ инвестиционных процессов в российской экономике в посткризисный период: проблемы и пути их решения / М. А. Николаев, М. Ю. Махотаева // Финансы и кредит. - 2015. - № 42 (666). - С. 2-18.

13. Звягинцева Н. А. Региональный рынок ценных бумаг как механизм привлечения инвестиций: оценка последствий вступления России в ВТО (на примере Иркутской области) / Н. А. Звягинцева // Известия Уральского государственного экономического университета. - 2013. - № 3/4. - С. 61-68.

14. Бахматов С. А. Инвестиции в условиях транзитивной экономики (методологический аспект) / С. А. Бахматов. - СПб. : Изд-во С.-Петерб. гос. ун-та экономики и финансов, 1999. - $136 \mathrm{c}$.

\section{References}

1. Messel E. O. Investment process management at regional level. Problemy sovremennoi ekonomiki $=$ Problems of Modern Economy, 2015, no. 2, pp. 97-102. (In Russian).

2. Savon I. V. System approach to investment process management at regional level. $F i$ nansovye issledovaniya $=$ Financial Research, 2012, no. 1, pp. 128-132. (In Russian).

3. Kobylinskaya G. V., Chapargina A. N. Regional'naya investitsionnaya sistema: tendentsii razvitiya i napravleniya sovershenstvovaniya [Regional investment system: development trends and improvement directions]. Apatity, Kola Science Centre of the Russian Academy of Sciences Publ., 2013. 164 p.

4. Gusev S. N. Investitsionnyi protsess $v$ otechestvennoi ekonomike i puti povysheniya effektivnosti gosudarstvennogo regulirovaniya natsio-nal'nogo nakopleniya [Investment process in domestic economy and ways of increasing efficiency of governmental regulation of national capital accumulation]. Kazan, Artifakt Publ., 2014. 204 p.

5. Litvinova V. V. Investitsionnaya privlekatel'nost' $i$ investitsionnyi klimat regiona [Investment attractiveness and region's investment climate]. Moscow, Financial University Publ., 2013. $116 \mathrm{p}$.

6. Aleksandrov G. A., Vyakina I. V., Skvortsova G. G. Investment climate and investment risks: methodology of analyzing interrelation and assessment. Natsional'nye interesy: prioritety $i$ bezopasnost' = National Interests: Priorities and Security, 2014, no. 22 (259), pp. 12-22. (In Russian).

7. Pykhov P. A. Diagnostics of natural resource capital of the territory. Ekonomika regio$n a=$ Regional Economy, 2013, no. 2, pp. 55-63. (In Russian).

8. Myzin A. L., Tatarkin A. I. Modelling national wealth of Russia's regions. Ekonomika regiona = Regional Economy, 2013, no. 4, pp. 53-65. (In Russian).

9. Igonina L. L. Financial capabilities of investment processes in Russian economy. Daidzhest-Finansy = Digest-Finance, 2016, no. 2 (238), pp. 2-14. (In Russian).

10. Kokushkina I. V. Region $v$ sisteme sovremennykh investitsionnykh protsessov [The region in the system of present-day investment processes]. Saint Petersburg, Spetsialnaya Literatura Publ., 2014. 256 p.

\section{Baikal Research Journal}


11. Tyutyukina E. B., Sedash T. N. Impact of credit and tax factors on developing investment activity of companies in basic economic industries. Finansy $i$ kredit $=$ Finance and Credit, 2014, no. 19 (595), pp. 9-16. (In Russian).

12. Nikolayev M. A., Makhotayeva M. Yu. The analysis of investment processes in the Russian economy during the post-crisis period: problems and solutions. Finansy $i$ kredit $=$ Finance and Credit, 2015, no. 42 (666), pp. 2-18. (In Russian).

13. Zvyagintseva N. A. Regional Securities Market as a Mechanism to Attract Investment: Assessing Effects of Russia's Entry into the WTO (as in Case of Irkutsk Oblast). Izvestiya Ural'skogo gosudarstvennogo ekonomicheskogo universiteta = Journal of the Ural State University of Economics, 2013, no. 3-4, pp. 61-68. (In Russian).

14. Bakhmatov S. A. Investitsii v usloviyakh tranzitivnoi ekonomiki (metodologicheskii as pekt) [Investments in terms of transitive economy (methodological aspect)]. Saint Petersburg State University of Economics and finances Publ., 1999. 136 p.

\section{Информация об авторе}

Попова Евгения Михайловна - ассистент, кафедра мировой экономики, предпринимательства и гуманитарных дисциплин, Читинский институт Байкальского государственного университета, 672002, г. Чита, ул. Анохина, 56, e-mail: p_e_m_2013@mail.ru.

\section{Author}

Evgeniya M. Popova - Assistant Lecturer, Chair of World Economy, Business and Humanities, Chita Institute, Baikal State University, 56 Anokhina St., 672002, Chita, Russian Federation; e-mail: p_e_m_2013@mail.ru.

\section{Библиографическое описание статьи}

Попова Е. М. Институциональная и социально-экономическая среда реализации регионального инвестиционного процесса / Е. М. Попова // Baikal Research Journal. — 2016. T. 7, № 6. - DOI: 10.17150/2411-6262.2016.7(6).8.

\section{Reference to article}

Popova E. M. Institutional and socio-economic environment of implementing regional in-vestment process. Baikal Research Journal, 2016, vol. 7, no. 6. DOI: 10.17150/24116262.2016.7(6).8. (In Russian).

\section{Baikal Research Journal}

